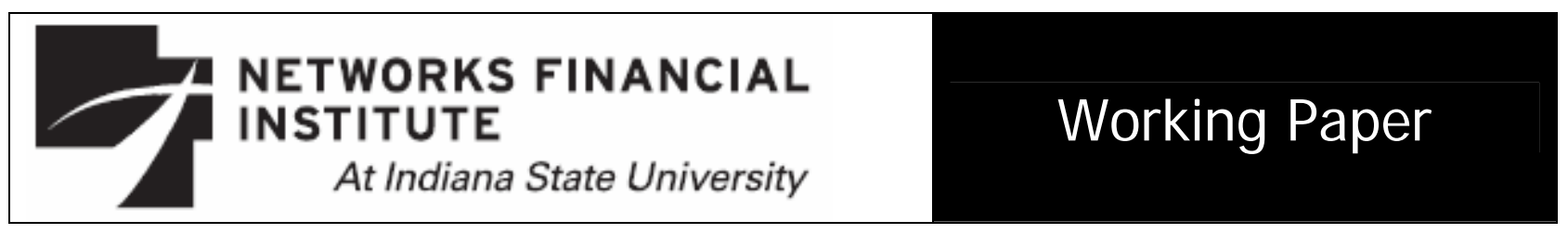

2007-WP-10

March 2007

\title{
Financial Development and Economic Growth: New Evidence from Panel Data
}

\section{Kabir Hassan and J ung-Suk Yu}

Abstract: This study provides new evidence on the role of financial development in accounting for economic growth. To derive feasible policy implications, we estimate not only unbalanced panel regressions with period fixed effects, but also variance decompositions of annual GDP growth rates to examine what proxy measures are most important in economic growth over time and how much they contribute to economic growth across geographic regions and income groups. We find strong linkages between financial development and economic growth in high-income OECD countries, but not in South Asian and Sub-Saharan African regions. Therefore, it may be necessary to make different efforts to achieve steady economic growth across geographic regions and income groups.

\section{About the Authors:}

Dr. Kabir Hassan is a tenured professor at the University of New Orleans and also holds a visiting research professorship at Drexel University, Philadelphia. He is a financial economist with consulting, research and teaching experiences in development finance, money and capital markets, corporate finance, investments, monetary economics, macroeconomics and international trade and finance. He has published five books, over 70 articles in refereed academic journals and has presented over 100 research papers at professional conferences globally.

Dr. J ung-Suk Yu is with the Samsung Economic Research Institute in Korea.

Keywords: economic growth, financial development

The views expressed are those of the individual author and do not necessarily reflect official positions of Networks Financial Institute. Please address questions regarding content to M. Kabir Hassan at mhassan@uno.edu. Any errors or omissions are the responsibility of the author.

NFI working papers and other publications are available on NFI's website (www. networksfinancialinstitute.org). Click "Research" and then "Publications/Papers." 


\section{Financial Development and Economic Growth: New Evidence from Panel Data}

\section{Kabir Hassan and J ung-Suk Yu}

\section{Introduction}

Although the relationship between financial development and economic growth has received a great deal of attention during the recent decades, there are conflicting views concerning the role that the financial system can play in economic growth. For example, while Levine (1997) believes that financial intermediaries enhance economic efficiency and, ultimately, growth by helping allocate capital to its best uses, Lucas (1988) asserts that the role of the financial sector in economic growth is 'over-stressed'. Notwithstanding the controversy, the modern theoretical literature (Romer 1986; Lucas 1988; Rebelo 1991; Grossman and Helpman 1991; Pagano, 1993 among others) on the finance-growth nexus combines endogenous growth theory and microeconomics of financial systems.

Furthermore, the main conclusions in both theoretical and empirical studies based on cross-country analysis are sensitive to the countries, estimation methods, data frequency, functional form of the relationship, and proxy measures chosen in the study (see Hassan and Bashir, 2003; Khan and Senhadji, 2000; Chuah and Thai, 2004; Al-Awad and Harb, 2005). Therefore, it is unreliable to only rely on the empirical results of cross-country regressions. It is also argued that the convergence tests obtained from cross-country studies are misleading, and that the variations in the results are hard to interpret (Arestis and Demetriades, 1997).

To mitigate the shortcoming of cross-sectional country-case studies, this paper examines the dynamic relationship between economic growth and financial development across geographic 
regions and income groups using panel data rather than using a large cross-section sample of countries. In retrospect, our interest in investigating the relationship between economic growth and financial development across geographic regions and income groups is motivated by many factors. First, it is argued that well-developed domestic financial sectors, such as high-income OECD countries, can significantly contribute to raising the savings rate, the investment rate and, hence, transmit to economic growth (see Becsi and Wang, 1997). Many developing countries have reformed their economic and financial systems to improve the efficiency of their financial intermediaries, achieve financial sector deepening, and promote growth. It is, therefore, necessary to document the progress achieved by these countries across geographic regions and income groups in revamping their financial system over the last decades and assess the links between these reforms and the economic performance.

Second, this study will allow us to take a closer look at a range of financial development indicators and draw some conclusions about their impact on economic growth represented by annual GDP growth rate. Third, we employ the unbalanced panel estimations with period fixed effects and various multivariate time-series analysis to establish the direction, timing, and strength of the causal link between the real and the financial sector across geographic regions and income groups so that we can explore important policy implications. Finally, rather than using heterogeneous cross-country samples, we investigate different geographic regions with a group of relatively homogeneous samples of countries, which makes it adequate for assessing the links between economic growth and financial development. ${ }^{1}$

\footnotetext{
${ }^{1}$ The World Bank only categorizes geographic regions for low and middle-income countries and high-income countries are not included in classification by geographic regions. Therefore, each geographic region has the homogeneity in the level of economic growth and financial development to some degree.
} 
In this paper, we find strong linkages between financial development and economic growth in high-income OECD countries. However, South Asian and Sub-Saharan African regions reveal very weak or no financial development and economic growth nexus based on the results of Granger causality tests. Therefore, we need to make different policy efforts across geographic regions and income groups because there is only a little probability that steady economic growth can be achieved by simply enhancing financial development in South Asian and Sub-Saharan African regions.

The paper is organized as follows. Section II provides a literature review. We describe the data and the proxy measures of financial development, real sector, and economic growth in Section III. Section IV describes the unbalanced panel estimations with period fixed effects and multivariate time-series methodology used in the paper. We analyze the empirical results in Section V. Section VI provides conclusions.

\section{Literature Review}

Ever since the pioneering contributions of McKinnon (1973) and Shaw (1973) on the role of financial development in promoting economic growth, the relationship between economic growth and financial development has still remained an important issue of debate among academicians and policymakers (De Gregorio and Guidotti, 1995). In early economic growth theory it is argued that economic development is a process of innovations whereby the interactions of innovations in both the financial and real sectors provide a driving force for dynamic economic growth. It is contended that exogenous technological progress determines the 
long-run growth rate while financial intermediaries are not explicitly modeled to affect the longrun growth rate.

However, there is now a growing theoretical and empirical body of literature on how financial intermediation mobilizes savings, allocates resources, diversifies risks, and contributes to economic growth (see Greenwood and Jovanovic, 1990; Jbili, Enders, and Treichel, 1997). The new growth theory argues that financial intermediaries and markets appear endogenously in response to the market incompleteness and, hence, contribute to long-run growth. Financial institutions and markets, who arise endogenously to mitigate the effects of information and transactions costs frictions, influence decisions to invest in productivity-enhancing activities through evaluating prospective entrepreneurs and funding the most promising ones. The underlying assumption here is that financial intermediaries can provide these evaluation and monitoring services more efficiently than individuals.

Levine (1997) and Khan and Senhadji (2000) survey a large amount of empirical research that deals with the relation between the financial sector and long-run growth. Levine (1997) identifies five functions that the financial system can accomplish to ameliorate information and transactions frictions and contribute to long-run growth. ${ }^{2}$ Khan and Senhadji (2000) also summarize the empirical evidence of country-case studies. They conclude that economic growth generally leads to financial deepening, suggesting that there exists a strong reverse causality between financial development and growth.

\footnotetext{
${ }^{2}$ According to Levine (1997), these five functions are: facilitating risk amelioration, acquiring information about investments and allocating resources, monitoring managers and exerting corporate control, mobilizing savings, and facilitating exchange.
} 
A number of recent papers have empirically tested the impact of both the financial sector and financial repression policies on the rate of economic growth. Since financial development is not easily measurable, papers attempting to study the link between financial deepening and growth have chosen a number of proxy measures and subsequently, have come up with different results (see King and Levine, 1992; Savvides, 1995; Khan and Senhadji, 2000; Hassan and Bashir, 2003; Chuah and Thai, 2004; Al-Awad and Harb, 2005, among others). Generally speaking, studies using different indicators of financial development not only find a positive correlation between the financial sector and growth, but also conclude that the development of bank credit has an important impact on economic growth.

\section{Data and Proxy Measures}

\section{A. Structuring the Panel Dataset}

Our sample periods covering 1960 through 2005 are an era of development of financial institutions and financial liberalization in many countries. It can also be characterized with output expansion, money growth, and increasing volume of investment. However, the pattern of growth of banks and money appears to differ considerably over time and across countries. Furthermore, our comprehensive original dataset includes 208 countries and have nested panel data structure from the World Bank’ World Development Indicators 2006 (WDI) database.

Therefore, to see how financial development and real sector link to economic growth, we follow the World Bank classifications which categorize all World Bank member economies and all other economies with populations of more than 30,000 by 7 geographic regions and 4 income groups as listed in Appendix A. Then, we obtain average values of proxy measures across 
countries within the same geographic regions and income groups to generate well-defined panel data structure with cross-sectional geographic regions and income groups and time-series proxy measures from 1960 to 2005.

Therefore, this data transformation enables us to consider both the heterogeneity of crosscountries and the homogeneity of geographic regions and income groups. Furthermore, our dataset also allows us to effectively estimate panel regression with fixed effects using whole dataset and to analyze various multivariate time-series models within each geographic region and income group without loss of generality. Therefore, it is possible to derive meaningful policy implications by dynamically examining different economic roles, causality, directions, and timing among proxy measures for financial development and economic growth across geographic regions and income groups.

\section{B. Proxy Measures for Financial Development and Economic Growth}

Various measures have been used in the literature to proxy for the 'level of financial development', ranging from interest rates to monetary aggregates, to the ratio of the size of the banking system to GDP (Khan and Senhadji, 2000; Chuah and Thai, 2004; Al-Awad and Harb, 2005 among others). For this study, we collect relevant proxy measures for financial development, real sector and economic growth from the World Bank' World Development Indicators 2006 (WDI) database for the period from 1960 to 2005. In our ensuing analysis, we use GDP growth rates (annual \%) as a proxy for economic growth (GDPG). We also utilize the following six variables to measure financial development and the size of real sector. Some of 
proxy measures for financial development incorporate information from banks and other financial intermediaries in addition to loan markets.

The first proxy is the domestic credit provided by banking sector as a percentage of GDP (DCBS). It is assumed that banks are not subject to mandated loans to priority sectors, or obligated to hold government securities. Therefore, higher DCBS indicates higher degree of dependence upon banking sector for financing. Another related measure is the domestic credit to private sector as a percentage of GDP (DCPS). A high ratio of domestic credit to GDP indicates a higher level of domestic investment, indicating higher output. We also use the ratio of M3 to GDP (M3) to measure the liquid liabilities in the economy. We use M3 as a financial depth indicator because monetary aggregates, such as M2 or M1, may be a poor proxy in that economies with underdeveloped financial systems may have a high ratio of money to GDP, as money is used as a store of value in the absence of other more attractive alternatives (Khan and Senhadji, 2000). A higher liquidity ratio means higher intensity of the banking system. The assumption here is that the size of the financial sector is positively associated with the financial services (see King and Levine, 1993).

The fourth indicator used is the ratio of gross domestic savings to GDP (GDS). Like the previous proxy, this measure also indicates the intensity of the financial intermediaries since it corresponds to more financial services and, hence, more financial development. Financial development is expected to benefit from higher GDS and, consequently, higher volume of investment. In most developing countries, financial repression and credit controls lead to negative real interest rates that reduce the incentives to save. According to this view (MckinnonShaw, 1973), a higher GDS resulting from a positive real interest rate stimulates investment and growth. Therefore, these measures have advantages over other measures used in the literature 
because most of the financial development occurs in the banking sector and, moreover, they are directly linked to investment and economic growth.

The fifth and sixth indicators used in this study are the ratio of trade to GDP (TRADE) and the ratio of general government final consumption expenditure to GDP (GCE), respectively. They effectively measure the size of real sector and the weight of fiscal policy. Many developing countries tend to heavily rely on international trades to achieve economic growth as financial liberalization is still in progress. In addition, some countries use expansionary or contractionary fiscal policies for steady economic growth by adjusting government spending.

\section{Summary Statistics of Proxy Measures}

Table I compares key financial and real indicators along with an economic growth proxy across geographic regions and income groups. We find that mean and median values are very close, implying stable time-series movements of proxy measures without extreme values during our sample periods covering from 1960 to 2005. For GDP growth rates, East Asia \& Pacific region shows the highest average (8\%) and maximum (11\%) values to reflect rapid economic expansion of many Asian countries, such as China and the Philippines in recent decades. The average (3\%) and maximum (6\%) GDPG of high-income OECD countries are significantly lower than those of other geographic regions. Noticeably, Latin America \& Caribbean (-3\%), South Asia (-3\%), Sub-Saharan Africa (-1\%), and East Europe (-6\%) regions appear to suffer from severe fluctuations of GDPG. They experience negative GDPG mainly due to economic recession or political instability prevalent in those regions. 
As expected, high-income OECD countries boast the highest average and minimum values of DCBS, DCPS, and M3 proxy measures to represent the relative sizes of financial system and financial depth. It is obvious that even developed countries with efficient financial intermediaries still tend to heavily rely on domestic credits provided by banking sector and have plenty of liquidity liabilities traded in their well-developed exchanges or financial institutions. However, financial depth indicators in South Asia and Sub-Saharan Africa regions are relatively small portions of GDP, implying insufficient credit in the private sectors and inefficient financial systems of those regions. For gross domestic savings, most regions show similar relative sizes as a percentage of GDP although countries located in East Asian \& Pacific region tend to have a higher propensity for saving compared with other geographic regions. For the real sector, summary statistics show a high dependency on international trade in the East Asia \& Pacific region, High-Income OECD, Middle East \& North Africa, and Sub-Saharan Africa regions. In addition, the government fiscal policy is one of the useful tools to control overall economic conditions, evidenced by about 10 - 20\% GCE without regard to geographic regions and income groups.

\section{Panel Estimations and Multivariate Time-Series Methodology}

\section{A. Unbalanced Panel Estimations with Period Fixed Effects}

To examine the general relationship between financial development, the real sector, and economic growth, we estimate a panel regression using our entire panel dataset including 7 cross-sectional geographic regions and multivariate 6 time-series proxy measures from 1960 to 2005. To correct for the presence of autocorrelation of GDPG and to explain unobserved period 
effects of GDPG, we also incorporate lagged annual growth rates and individual fixed effects as explanatory variables. In addition, we find that some of proxy measures have missing years for a few cross-sectional geographic regions in our panel data structure. Therefore, we perform the following unbalanced panel estimations ${ }^{3}$ with period fixed effects using panel least squares methods.

$$
\begin{aligned}
G D P G_{i t} & =\beta_{0}+\beta_{1} \cdot G D P G_{i, t-1}+\beta_{2} \cdot D C B S_{i, t}+\beta_{3} \cdot D C P S_{i, t} \\
& +\beta_{4} \cdot M 3+\beta_{5} \cdot G D S_{i, t}+\beta_{6} \cdot T R A D E_{i, t}+\beta_{7} \cdot G C E_{i, t}+F E_{t}+\varepsilon_{i t}
\end{aligned}
$$

where $i$ is the 7 cross-sectional geographic regions, $t$ is the time periods of proxy measures from 1960 to $2005, G D P G_{i, t-1}$ is the lagged annual growth rates, and $F E_{t}$ is the unobserved individual period fixed effects.

In this specification, the dependent variable is annual GDP growth rates as a proxy measure for economic growth and explanatory variables include 6 proxy measures for financial development and real sector combined with constant, lagged term of GDPG, and fixed effects. Furthermore, we assume that $F E_{t}$ is correlated with other explanatory variables and the explanatory variables are exogenous after we take out the unobserved effect, $F E_{t}$.

\section{B. Multivariate Time-Series Models}

To consider dynamic causality, direction, and timing between financial development and economic growth, we also estimate a number of vector autoregressive (VAR) models and ask whether and what proxy measures Granger-cause economic growth. Granger causality tests

\footnotetext{
${ }^{3}$ We use the entire panel to run dynamic panel regression in Equation (1). More specifically, the panel dataset includes the 7 cross-sectional geographic regions and the time periods of proxy measures from 1960 to 2005.
} 
allow us to overcome endogeneity problem in panel regressions in that VAR equations consider all variables endogenous. In the analyzing the results from the VAR model, the focus will be placed on two tools: impulse response function (IRF) and forecast error variance decomposition (FEVD). Impulse response functions show how one variable responds over time to a single innovation in itself or in another variable. Innovations in the variables are represented by shocks to the error terms in the equations. More importantly, we compute forecast error variance decompositions (FEVD) of GDPG to examine what proxy measures are most important in economic growth over time and how much they contribute to economic growth.

Our VAR specification includes total 7 variables including proxy measures for financial development (DCBS, DCPS, M3, and GDS), real sector (TRADE and GCE), and economic growth (GDPG) across 7 geographic regions. Formally, the VAR model is expressed as

$$
Y(t)=C+\sum_{s=1}^{m} A(s) Y(t-s)+e(t)
$$

where $Y(t)$ is a $7 \times 1$ column vector of 7 variables including proxy measures, and $C$ and $A(s)$ are, respectively, $7 \times 1$ and $7 \times 7$ matrices of coefficients, $m$ is the lag length, and $e(t)$ is the $7 \times 1$ column vector of forecast errors of the best linear predictor of $Y(t)$ using all the past $Y(s)$. By construction, $e(t)$ is uncorrelated with all the past $Y(s)$. If this is combined with the fact that $e(t)$ is also a linear combination of current and past $Y(t), e(t)$ is serially uncorrelated. The $i j$-th component of $A(s)$ measures the direct effect that a change in the return to the $j$-th variable would have on the $i$-th variable in $s$ periods. As can be seen from Equation (2), the 
right-hand side of each equation contains exactly the same terms, i.e., a constant, lagged value of each variable, and the error term.

However, in the autoregressive systems such as Equation (2), especially the coefficients of the regression equations containing complicated cross-equation feedbacks are difficult to describe intuitively. Therefore, as shown by Sims (1980), it is better to analyze the system's reaction to typical random shocks or, equivalently, trace out the system's moving average representation. By successive substituting on the right-hand side of Equation (2), we can obtain a moving average representation as follows,

$$
Y(t)=\sum_{s=0}^{x} B(s) e(t-s)
$$

which represents $Y(t)$ as a linear combination of current and past one-step-ahead forecast errors or 'innovations'. In a moving average representation, $x$ is the lag length.

Innovations, $e(t)$, are defined as

$$
e(t)=Y(t)-P[Y(t) \mid Y(t-1), Y(t-2), \cdots]
$$

where $P$ denotes the linear least squares projection of $Y(t)$ in the space spanned by $[Y(t-1), Y(t-2), \cdots]$. The moving average representation of Equation (3) enables us to trace out the reactions of variables to shocks, $e(t)$, in the form of unexpected developments in a specific variables. The $i j$-th component of $B(s)$ shows the response of the $i$-th variable in $s$ periods after a unit random shock in the $j$-th variables and none in other variables. The $i j$-th component of $B(s)$ represents the conditional expectation at time $t$ of changes of the $i$-th 
variable in $s$ periods caused by a unit change in the $j$-th variable, conditional on the information available at time $t$.

Although $e(t)$ is serially uncorrelated by construction, the components of $e(t)$ may be contemporaneously correlated. In order to observe the distinct response patterns that the VAR system may display, it is useful to transform the error terms. To achieve this goal, we choose a lower triangular matrix $V$ and obtain the orthogonalized innovations $u$ from $e=V u$. It is noted that the transformed innovation, $u(t)$, has an identity covariance matrix, such that $E\left(e e^{\prime}\right)=S$ and $V V^{\prime}=S$. Upon making an orthogonalized transformation to $e(t)$, Equation (3) can be rewritten as follows.

$$
Y(t)=\sum_{s=0}^{x} B(s) V u(t-s)=\sum_{s=0}^{x} C(s) u(t-s)
$$

where $C(s)=B(s) V$. Then the ij-th component of $C(s)$ represents the impulse (or reflex) response of the $i$-th variable in $s$ periods to a shock of one standard error in the $j$-th variable. To be consistent with the historical correlation pattern of innovations, we introduce a contemporaneous shock in each equation that is equal to the corresponding element in the $j$-th column of matrix $V$ when we introduce one standard deviation shock in the $j$-th variable.

Another advantage of using orthogonalized innovations is that we can also allocate the variance of each element in $Y$ to sources in elements of $u$, since $u$ is serially and contemporaneously uncorrelated. The orthogonalization provides the quantity, $\sum C_{i j}(s)$, which is the component of forecast error variance in the $t+1$ step ahead forecast of $Y_{i}$, which is accounted for by innovations in $Y_{j}$. This decomposition of forecast error variance provides a 
measure of the overall relative importance of the variables in generating the fluctuations in proxy measures in their own and other variables.

\section{Empirical Results}

\section{A. Analysis of Panel Regressions and Impulse Response Functions based on Panel Dataset}

We report parameter estimates for unbalanced panel regressions with period fixed effects

in Table II. We find that GDP growth rate (GDPG) has a strong positive relationship with lagged annual growth rate (GDPG(-1)), domestic credit to private sector (DCPS), liquid liabilities (M3) and gross domestic savings (GDS). However, GDPG shows a negative association with domestic credit provided by banking sector (DCBS), Trade (TRADE), and government consumption expenditure (GCE).

Since our goal is to assess the role of the financial and real sector in economic growth, we also investigate the dynamic relationships among proxy measures and how our various variables of financial development affect economic growth. Panel A of Figure 1 illustrates how GDPG responds over time to Cholesky-one-standard-deviation innovation in another variable using all the geographic regions from our panel dataset. We observe that the general directions of impulse responses of GDPG are consistent with the signs of coefficients in panel regressions.

GDPG responds positively to innovation in M3 (financial depth). A positive shock to DCPS and GDS has a significant positive impact on GDPG. While a positive shock to DCBS and GCE has negative impacts on GDPG. A shock to TRADE rapidly dies out after 3 years. GDPG has positive impacts on all financial and real variables included in this system except DCBS and GCE. It appears that higher dependency on banks tend to negatively affect economic 
growth, suggesting strong needs of diversifying financing sources. In addition, abuse of discretion to perform fiscal policy could worsen economic growth in many countries, evidenced by a negative sign of the GCE coefficient in a panel regression and negative impulse responses of GDPG to a single shock in GCE.

B. Analysis of VAR results, Dynamic Causality, and Policy Implications across Geographic Regions and Income Groups

We decompose the forecast error of the endogenous variable GDPG over different time horizons into components attributable to unexpected innovations (or shocks) in proxy measures in the dynamic VAR system. The forecast error variance decompositions (FEVD) of GDPG in VAR are presented across geographic regions and income groups in Table III. In addition, GDPG is said to be Granger-caused by proxy measures if proxy measures help in the prediction of GDPG, or equivalently if the coefficients on the lagged proxy measures are statistically significant. We report the results of Granger causality tests in Table IV.

\section{East Asia \& Pacific (Low and Middle Income Groups)}

The results from Table III show that M3 shocks explain 6.7368\% of GDPG. DCBS, TRADE and GCE shocks explain 12.1350\%, 7.6281\%, and 6.9521\% after 10 years ahead, respectively. We know from Table II and Panel A of Figure 1 that DCBS, TRADE, and GCE have negative relationships with GDPG. Therefore, for East Asia \& Pacific countries, it will be beneficial to further increase M3 and diversify financing sources to reduce DCBS. 
However, Granger causality tests in Table IV imply that there is a very weak relationship between financial development and economic growth in the short run. ${ }^{4}$ Therefore, it will be necessary to perform stable and predictable government policy to achieve steady economic growth because financial development will only effectively affect economic growth in the long run according to the signs of coefficients in panel regression.

\section{High-Income OECD}

For the high-income OECD countries, Table III implies that proxy measures for financial development play a more important role in explaining GDPG fluctuations compared to those of real sector. For example, M3 shocks explain 14.6310\% of GPDG fluctuations and DCBS shocks explain $9.4436 \%$, while shocks of DCPS, GDS, TRADE, and GCE explain less than $6 \%$ of GDPG fluctuations. From Table IV, we find that most proxy measures for financial development Granger cause GDPG. Therefore, in the Panel B of Figure 1, we illustrate the impulse response functions of GDPG to Cholesky-one- standard-deviation innovations in DCBS, DCPS, M3, and TRADE.

A shock to M3 builds to a peak immediately and significantly declines after 2 years, then gradually increase afterwards. We find the similar patterns for the DCBS and DCPS as that of M3. However, responses of GDPG to a single shock in TRADE are somewhat opposite in that a shock initially decline and then increase after two years. For high-income OECD countries,

\footnotetext{
${ }^{4}$ Note that the emphasis in Granger causality tests is on short-run relationship because the results of panel regression and cointegration tests strongly imply the presence of long-run linkages between financial development and economic growth. (The results of cointegration tests are not shown to conserve the space and are available upon requests.)
} 
well-developed financial systems are crucial to achieve economic growth and financial development is closely related with economic growth both in the short- and long run. Therefore, it is recommended to further maintain efficient financial systems by increasing M3 and domestic credit to private sector.

\section{Latin America \& Caribbean (Low and Middle Income Groups)}

Table III shows that only DCPS explains more than 10\% of GDPS fluctuations after 10 years ahead. Other proxy measures for financial development and real sectors can explain only small portions of GDPG, implying the decline of the contribution of financial depth (M3) in explaining the variation in GDPG, while the contribution of DCPS in explaining GDPG variation has increased. In the short run, it appears that only M3 Granger causes GDPG as in Table IV. In general, M3 has a positive impact on GDPG. In other words, the impact of M3 on GDPG remains positive except for 3 and 6 years ahead. Therefore, for Latin America \& Caribbean countries, it will be beneficial to increase M3 in the short run. However, in the long run, it will be more efficient to raise domestic credit to the private sector so that economy has more capacity to attain a higher level of domestic investment.

\section{Middle East \& North Africa}

For Middle East \& North Africa countries, GDPG only explains $33.3052 \%$ of its variation, which is a significantly lower portion compared to other geographic regions. We find that all of proxy measures for financial development explain very high portions of variations in GDPG after 10 years ahead. For example, M3 explains 29.0321\% of GDPG fluctuation. 
Similarly, DCPS and DCBS explain $18.9425 \%$ and $10.1718 \%$ of variations in GDPG, respectively, after 10 years ahead. This finding strongly indicates that financial development plays an important role in economic growth.

In the short run, Granger causality tests show that only M3 shock has a positive impact on GDPG. Therefore, the results indicate that efforts to reform and deepen the financial system in the Middle East \& North Africa region would prove fruitful. In the long run, the continuing progress in financial liberalization and integration with developed countries would be also helpful to further enhance efficiency and liquidity of financial markets in Middle East \& North Africa region, resulting in stable economic growth.

\section{South Asia (Low and Middle Income Groups)}

In the VAR system for South Asia region, M3 accounts for only 4.5029\% of the GDPG fluctuations. Other key financial development indicators, such as DCBS and DCPS account for 9.9847 and $9.6445 \%$ of variations in GDPG, respectively. For real sector, although GCE explain moderate $4.2476 \%$ of GDPG, TRADE accounts for only $0.9684 \%$ of GDPG. Even in the short run, it appears that none of the proxy measures for financial development and the real sector Granger cause GDPG. Therefore, the variance decomposition results strongly imply that it is necessary to increase domestic credit to private sector so that countries in South Asia region can be equipped with more efficient and liquid financial intermediaries in the long run. 


\section{Sub-Saharan Africa (Low and Middle Income Groups)}

The variance decomposition results indicate that GDPG accounts for $91.0878 \%$ of its variation, implying a very weak effect of the financial and real variables on GDPG. All of proxy measures account for less than $4 \%$ of variations in GDPG after 10 years ahead. Sub-Saharan Africa region does not have proxy measures which Granger cause GDPG, which partly explains why many countries in Sub-Saharan Africa region still remain low or lower middle income group. Therefore, similar to South Asia in the short run, we do not find the specific relationship between financial development and economic growth either. However, it is still important to raise domestic credit to private sector until countries in Sub-Saharan Africa region have more capacity to attract higher level of investments for long-run economic growth.

\section{Conclusions}

We examined a panel regression with cross-sectional geographic regions and time-series proxy measures to establish linkage and directions between the financial development and economic growth. In addition, we also analyzed various multivariate time-series model, such as VAR, forecast error variance decompositions, impulse response functions, and Granger causality tests to derive feasible policy implications.

We argue that different policy should be performed to achieve the target of economic growth due to the distinct stage of financial development across geographic regions and income

groups. For example, we find the strong linkages between financial development and economic growth in high-income OECD countries, but not in South Asia and Sub-Saharan Africa regions. 
Therefore, we also need to consider institutional characteristics, including the type of financial system and policies to explain the differences between regions. 


\section{Appendix A: Geographic Classification and Countries}

\section{Geographic regions Countries}

East Asia \& Pacific

$(n=24)$

East Europe \& Central Asia $(n=27)$

High-Income OECD $(n=24)$

Latin America \& Caribbean $(n=32)$

Middle East \& North Africa $(n=14)$

South Asia

$(n=8)$

Sub-Saharan Africa $(n=48)$
American Samoa, Cambodia, China, Fiji, Indonesia, Kiribati, Korea, Dem. Rep., Lao PDR, Malaysia, Marshall Islands, Micronesia, Fed. Sts., Mongolia, Myanmar, Northern Mariana Islands, Palau, Papua New Guinea, Philippines, Samoa, Solomon Islands, Thailand, Timor-Leste, Tonga, Vanuatu, Vietnam

Albania, Armenia, Azerbaijan, Belarus, Bosnia and Herzegovina, Bulgaria, Croatia, Czech Republic, Estonia, Georgia, Hungary, Kazakhstan, Kyrgyz Republic, Latvia, Lithuania, Macedonia, FYR, Moldova, Poland, Romania, Russian Federation, Serbia and Montenegro, Slovak Republic, Tajikistan, Turkey, Turkmenistan, Ukraine, Uzbekistan

Australia, Austria, Belgium, Canada, Denmark, Finland, France, Germany, Greece, Iceland, Ireland, Italy, Japan, South Korea, Luxembourg, Netherlands, New Zealand, Norway, Portugal, Spain, Sweden, Switzerland, United Kingdom, United States

Antigua and Barbuda, Argentina, Barbados, Belize, Bolivia, Brazil, Chile, Colombia, Costa Rica, Cuba, Dominica, Dominican Republic, Ecuador, El Salvador, Grenada, Guatemala, Guyana, Haiti, Honduras, Jamaica, Mexico, Nicaragua, Panama, Paraguay, Peru, St. Kitts and Nevis, St. Lucia, St. Vincent and the , Grenadines, Suriname, Trinidad and Tobago, Uruguay, Venezuela, RB

Algeria, Djibouti, Egypt, Arab Rep., Iran, Islamic Rep., Iraq, Jordan, Lebanon, Libya, Morocco, Oman, Syrian Arab Republic, Tunisia, West Bank and Gaza, Yemen, Rep.

Afghanistan, Bangladesh, Bhutan, India, Maldives, Nepal, Pakistan, Sri Lanka

Angola, Benin, Botswana, Burkina Faso, Burundi, Cameroon, Cape Verde, Central African Republic, Chad, Comoros, Congo, Dem. Rep., Congo, Rep., Côte d'Ivoire, Equatorial Guinea, Eritrea, Ethiopia, Gabon, Gambia, Ghana, Guinea, Guinea-Bissau, Kenya, Lesotho, Liberia, Madagascar, Malawi, Mali, Mauritania, Mauritius, Mayotte, Mozambique, Namibia, Niger, Nigeria, Rwanda, São Tomé and Principe, Senegal, Seychelles, Sierra Leone, Somalia, South Africa, Sudan, Swaziland, Tanzania, Togo, Uganda, Zambia, Zimbabwe

Note: This table classifies all World Bank member economies and all other economies with populations of more than 30,000. Geographic classifications are for low-income and middle-income economies only. We include HighIncome OECD countries into geographic regions for analysis purpose because they are a representative group of developed countries. Except high-income OECD countries, the remaining low or middle income groups are sometimes referred to as developing economies (Economies are divided among income groups according to 2004 gross national income (GNI) per capita. The groups are: low income, $\$ 825$ or less; lower middle income, $\$ 826-$ 3,255; upper middle income, \$3,256 - 10,065; and high income, \$10,066 or more) based on World Bank classification.

Sources: World Bank’s World Development Indicators 2006 (WDI) database 


\section{References}

Al-Awad, M., and N. Harb, 2005, Financial Development and Economic Growth in the Middle East, Applied Financial Economics 15.

Arestis, P., and P. Demetriades, 1997, Financial Development and Economic Growth: Assessing the Evidence, The Economic Journal 107, 783-799.

Becsi, Z., and P. Wang, 1997, Financial Development and Growth, Economic Review 82, 46-62.

Chuah, H., and W. Thai, 2004, Financial Development and Economic Growth: Evidence from Causality Tests for the GCC Countries, IMF Working Paper.

De Gregorio, J., and P. Guidotti, 1995, Financial Development and Economic Growth, World Development 23, 433-448.

Hassan, M., and A. Bashir, 2003, Financial Development and Economic Growth in the Middle East, Working Paper, The $6^{\text {th }}$ International Conference in Islamic Economics, Manama, Bahrain.

Greenwood, J., and B. Jovanovic, 1990, Financial Development, Growth, and the Distribution of Income, Journal of Political Economy 98, 1076-1107.

Grossman, G., and E. Helpman, 1991, Quality Ladders in the Theory of Growth, Review of Economic Studies 58, 43-61.

Jbili, A., K. Enders, and V. Treichel, 1997, Financial Reforms in Algeria, Morocco, and Tunisia: A Preliminary Assessment, IMF Working Paper.

Khan, M., and A. Senhadji, 2000, Financial Development and Economic Growth: An Overview, IMF Working Paper.

King, R., and R. Levine, 1992, Finance and Growth: Schumpeter Might be Right, Quarterly Journal of Economics 108, 717-738. 
King, R., and R. Levine, 1993, Finance, Entrepreneurship, and Growth: Theory and Evidence, Journal of Monetary Economics 32, 513-542.

Levine, R., 1997, Financial Development and Economic Growth: Views and Agenda, Journal of Economic Literature XXXV, 688-726.

Lucas, R. E., 1988, On the Mechanics of Economic Development, Journal of Monetary Economics 22, 3-42.

McKinnon, R. I., 1973, Money and Capital in Economic Development, Washington, DC: Brookings Institution.

Pagano, M., 1993, Financial Markets and Growth: An Overview, European Economic Review 37, 613-622.

Rebelo, S. T., 1991, Long-Run Policy Analysis and Long-Run Growth, Journal of Political Economy 99, 500-521.

Romer, P. M., 1986, Increasing Returns and Long-Run Growth, Journal of Political Economy 94, 1002-1037.

Savvides, A., 1995, Economic Growth in Africa, World Development 23, 449-458.

Shaw, E. S., 1973, Financial Deepening in Economic Development, New York: Oxford University Press.

Sims, C., 1980, Macroeconomics and Reality, Econometrica 48, 1-48. 


\section{Table I}

\section{Summary Statistics of Proxy Measures}

\begin{tabular}{|c|c|c|c|c|c|c|c|}
\hline \multirow{2}{*}{$\begin{array}{l}\text { Proxy } \\
\text { Measures }\end{array}$} & \multirow{2}{*}{$\begin{array}{l}\text { Economic } \\
\text { Growth } \\
\text { GDPG }\end{array}$} & \multicolumn{4}{|c|}{ Financial Development } & \multicolumn{2}{|c|}{ Real Sector } \\
\hline & & DCBS & DCPS & M3 & GDS & TRADE & GCE \\
\hline \multicolumn{8}{|c|}{ East Asia \& Pacific } \\
\hline Mean (Med) & $8(8)$ & $79(75)$ & $74(75)$ & $76(70)$ & $34(34)$ & $49(49)$ & $11(11)$ \\
\hline Max (Min) & $11(2)$ & $134(37)$ & $110(41)$ & $141(28)$ & $38(28)$ & $82(49)$ & $13(9)$ \\
\hline \multicolumn{8}{|c|}{ East Europe \& Central Asia (Low and Middle Income Groups) } \\
\hline Mean (Med) & $2(2)$ & $36(37)$ & $21(22)$ & $34(35)$ & $22(22)$ & $72(71)$ & $17(17)$ \\
\hline Max (Min) & $7(-6)$ & $40(32)$ & $27(17)$ & $40(29)$ & $24(20)$ & $84(61)$ & $19(16)$ \\
\hline \multicolumn{8}{|c|}{ High-Income OECD } \\
\hline Mean (Med) & $3(3)$ & $115(110)$ & 108 (99) & $84(81)$ & $23(22)$ & $33(34)$ & $18(18)$ \\
\hline Max (Min) & $6(0)$ & $156(75)$ & $156(75)$ & $103(63)$ & $26(19)$ & $45(23)$ & $19(16)$ \\
\hline \multicolumn{8}{|c|}{ Latin America \& Caribbean (Low and Middle Income Groups) } \\
\hline Mean (Med) & $3(4)$ & $50(50)$ & $31(30)$ & $29(29)$ & $21(21)$ & $30(28)$ & $12(10)$ \\
\hline Max (Min) & $8(-3)$ & $103(23)$ & $53(16)$ & $41(19)$ & $24(19)$ & $49(19)$ & $15(9)$ \\
\hline \multicolumn{8}{|c|}{ Middle East \& North Africa (Low and Middle Income Groups) } \\
\hline Mean (Med) & $4(3)$ & $66(67)$ & $36(38)$ & $65(64)$ & $22(21)$ & $57(56)$ & $17(17)$ \\
\hline Max (Min) & $6(2)$ & $71(59)$ & $41(29)$ & $72(58)$ & $27(16)$ & $67(50)$ & $18(16)$ \\
\hline \multicolumn{8}{|c|}{ South Asia (Low and Middle Income Groups) } \\
\hline Mean (Med) & $5(6)$ & $42(45)$ & $23(23)$ & $39(40)$ & $17(18)$ & $21(19)$ & $10(10)$ \\
\hline Max (Min) & $9(-3)$ & $56(27)$ & $36(12)$ & $62(24)$ & $23(12)$ & $41(19)$ & $12(8)$ \\
\hline \multicolumn{8}{|c|}{ Sub-Saharan Africa (Low and Middle Income Groups) } \\
\hline Mean (Med) & $3(3)$ & $38(41)$ & 42 (39) & 33 (33) & 19 (19) & $56(56)$ & 15 (15) \\
\hline Max (Min) & $8(-1)$ & 47 (27) & $67(26)$ & 40 (29) & $26(15)$ & $66(47)$ & $18(11)$ \\
\hline
\end{tabular}


Table II

Parameter Estimates for Panel Regression with Fixed Effects

\begin{tabular}{|c|c|c|}
\hline Variable & Coefficient & $p$-value \\
\hline \multicolumn{3}{|l|}{ Dependent variable (Proxy measure for economic growth) } \\
\hline \multicolumn{3}{|l|}{ Annual \% of GDP Growth rate (GDPG) } \\
\hline \multicolumn{3}{|l|}{ Explanatory variables } \\
\hline \multicolumn{3}{|l|}{ (Proxy measures for financial development and real sector) } \\
\hline Constant $(C)$ & 3.8780 & {$[0.0016]$} \\
\hline Lagged annual growth rate (GDPG(-1)) & 0.2881 & [0.0001] \\
\hline Domestic credit provided by banking sector as \% of GDP (DCBS) & -0.0707 & [0.0006] \\
\hline Domestic credit to private sector as \% of GDP (DCPS) & 0.0330 & [0.0181] \\
\hline Liquid liabilities as \% of GDP (M3) & 0.0449 & [0.0095] \\
\hline Gross domestic savings as \% of GDP (GDS) & 0.1428 & [0.0005] \\
\hline Trade as \% of GDP (TRADE) & -0.0382 & [0.0197] \\
\hline \multirow[t]{2}{*}{ General government final consumption expenditure as \% of GDP (GCE) } & -0.1510 & [0.0423] \\
\hline & F-Statistic & $p$-value \\
\hline$R^{2}=0.5858, \overline{R^{2}}=0.4683$ & 4.9829 & {$[0.0000]$} \\
\hline$L R=-404.5868, \mathrm{AIC}=4.4958, \mathrm{SC}=5.2379$ & & \\
\hline
\end{tabular}

Note: We perform the following unbalanced panel estimations with period fixed effects using panel least squares methods.

$$
\begin{aligned}
G D P G_{i t} & =\beta_{0}+\beta_{1} \cdot G D P G_{i, t-1}+\beta_{2} \cdot D C B S_{i, t}+\beta_{3} \cdot D C P S_{i, t} \\
& +\beta_{4} \cdot M 3+\beta_{5} \cdot G D S_{i, t}+\beta_{6} \cdot T R A D E_{i, t}+\beta_{7} \cdot G C E_{i, t}+F E_{t}+\varepsilon_{i t}
\end{aligned}
$$

where $i$ is the 7 cross-sectional geographic regions, $t$ is time periods of proxy measures from 1960 to 2005, $G D P G_{i, t-1}$ is lagged annual growth rates, and $F E_{t}$ is unobserved individual period fixed effects. 


\section{Table III}

\section{Forecast Error Variance Decompositions of Economic Growth in VAR}

\begin{tabular}{|c|c|c|c|c|c|c|c|}
\hline Period & GDPG & DCBS & DCPS & M3 & GDS & TRADE & GCE \\
\hline \multicolumn{8}{|c|}{ East Asia \& Pacific (Low and Middle Income Groups) } \\
\hline 2 years ahead & 94.0508 & 1.6627 & 0.9871 & 0.0035 & 0.6275 & 0.0120 & 2.6564 \\
\hline 5 years ahead & 63.9155 & 13.2102 & 3.0563 & 3.2388 & 2.2149 & 7.7496 & 6.6147 \\
\hline 10 years ahead & 57.0856 & 12.1350 & 3.9925 & 6.7368 & 5.4698 & 7.6281 & 6.9521 \\
\hline \multicolumn{8}{|c|}{ High-Income OECD } \\
\hline 2 years ahead & 79.0244 & 6.8737 & 4.9382 & 4.9833 & 1.0928 & 1.9653 & 1.1223 \\
\hline 5 years ahead & 64.1623 & 9.5882 & 5.5084 & 14.1325 & 3.5821 & 1.7679 & 1.2586 \\
\hline 10 years ahead & 61.8540 & 9.4436 & 5.8855 & 14.6310 & 3.6382 & 2.2912 & 2.2564 \\
\hline \multicolumn{8}{|c|}{ Latin America \& Caribbean (Low and Middle Income Groups) } \\
\hline 2 years ahead & 84.1773 & 0.1178 & 5.8758 & 7.1139 & 0.4902 & 2.1463 & 0.0788 \\
\hline 5 years ahead & 72.6061 & 1.6025 & 13.3984 & 5.4934 & 3.6248 & 2.7670 & 0.5078 \\
\hline 10 years ahead & 76.5156 & 1.4595 & 12.3759 & 3.4449 & 3.4525 & 2.3707 & 0.3810 \\
\hline \multicolumn{8}{|c|}{ Middle East \& North Africa (Low and Middle Income Groups) } \\
\hline 2 years ahead & 72.5349 & 0.2488 & 3.9778 & 22.1975 & 0.1388 & 0.9022 & NA \\
\hline 5 years ahead & 42.7558 & 12.1855 & 10.5136 & 24.2191 & 6.4517 & 3.8742 & NA \\
\hline 10 years ahead & 33.3052 & 10.1718 & 18.9425 & 29.0321 & 5.2971 & 3.2514 & $N A$ \\
\hline \multicolumn{8}{|c|}{ South Asia (Low and Middle Income Groups) } \\
\hline 2 years ahead & 82.5293 & 1.4129 & 11.4056 & 2.6348 & 1.9683 & 0.0355 & 0.0137 \\
\hline 5 years ahead & 66.6133 & 11.5782 & 12.2418 & 2.3345 & 2.9483 & 0.6269 & 3.6570 \\
\hline 10 years ahead & 66.4804 & 9.9847 & 9.6445 & 4.5029 & 4.1715 & 0.9684 & 4.2476 \\
\hline \multicolumn{8}{|c|}{ Sub-Saharan Africa (Low and Middle Income Groups) } \\
\hline 2 years ahead & 91.4286 & 0.0365 & 1.3642 & 1.7158 & 0.2152 & 4.0413 & 1.1983 \\
\hline 5 years ahead & 90.4272 & 1.3374 & 3.7685 & 1.1743 & 0.2346 & 2.2930 & 0.7650 \\
\hline 10 years ahead & 91.0878 & 1.0284 & 3.5993 & 1.2770 & 0.9115 & 1.2514 & 0.8446 \\
\hline
\end{tabular}

Note: We do not perform VAR analysis for East Europe \& Central Asia region because of the insufficient number of observations resulting from many missing values during our sample periods covering from 1960 to 2005. 
Table IV

\section{Granger Causality Tests across Geographic Regions}

\begin{tabular}{|c|c|c|c|c|}
\hline East Asia \& Pacific & \multicolumn{2}{|c|}{ Null Hypothesis $\left(H_{o}\right)$} & F-Statistic & $p$-value \\
\hline \multirow{4}{*}{ Financial Development } & DCBS & \multirow{6}{*}{$\begin{array}{l}\text { does not Granger } \\
\text { cause GDPG }\end{array}$} & 0.2175 & {$[0.8063]$} \\
\hline & DCPS & & 0.6100 & [0.5527] \\
\hline & M3 & & 0.5453 & {$[0.5876]$} \\
\hline & GDS & & 0.5403 & {$[0.5878]$} \\
\hline Real Sector & TRADE & & 0.5401 & {$[0.5886]$} \\
\hline Neai vectur & GCE & & 0.8238 & {$[0.4479]$} \\
\hline \multicolumn{5}{|l|}{ High-Income OECD } \\
\hline & DCBS & \multirow{6}{*}{$\begin{array}{l}\text { does not Granger } \\
\text { cause GDPG }\end{array}$} & 3.3292 & [0.0486] \\
\hline Cinonciol Doylonmont & DCPS & & 3.4851 & {$[0.0427]$} \\
\hline Financial Development & M3 & & 5.0671 & {$[0.0135]$} \\
\hline & GDS & & 1.0929 & {$[0.3478]$} \\
\hline & TRADE & & 10.5874 & [0.0003] \\
\hline Real sector & GCE & & 0.7371 & {$[0.4867]$} \\
\hline \multicolumn{5}{|c|}{ Latin America \& Caribbean } \\
\hline & DCBS & \multirow{6}{*}{$\begin{array}{l}\text { does not Granger } \\
\text { cause GDPG }\end{array}$} & 1.8143 & [0.1793] \\
\hline Financial Deyelonment & DCPS & & 0.8305 & {$[0.4450]$} \\
\hline Findictal Leveropintint & M3 & & 3.3974 & [0.0459] \\
\hline & GDS & & 0.4122 & [0.6657] \\
\hline Real Sector & TRADE & & 1.3269 & {$[0.2795]$} \\
\hline & GCE & & 0.4265 & [0.6565] \\
\hline \multicolumn{5}{|c|}{ Middle East \& North Africa } \\
\hline & DCBS & \multirow{6}{*}{$\begin{array}{l}\text { does not Granger } \\
\text { cause GDPG }\end{array}$} & 1.3154 & {$[0.2906]$} \\
\hline Fingncial Doylonmont & DCPS & & 0.0190 & [0.9812] \\
\hline Financial Development & M3 & & 3.8920 & {$[0.0350]$} \\
\hline & GDS & & 0.3083 & {$[0.7377]$} \\
\hline & TRADE & & 0.5582 & [0.5798] \\
\hline Real sector & GCE & & 0.0296 & [0.9710] \\
\hline \multicolumn{5}{|l|}{ South Asia } \\
\hline & DCBS & \multirow{6}{*}{$\begin{array}{l}\text { does not Granger } \\
\text { cause GDPG }\end{array}$} & 3.2307 & {$[0.0527]$} \\
\hline Financial Develonment & DCPS & & 2.2331 & {$[0.1236]$} \\
\hline Finalictar Leveropintilt & M3 & & 2.4481 & [0.1025] \\
\hline & GDS & & 2.1272 & [0.1357] \\
\hline Real Sector & TRADE & & 1.8912 & [0.1674] \\
\hline Kedr sector & GCE & & 1.9029 & [0.1656] \\
\hline \multicolumn{5}{|l|}{ Sub-Saharan Africa } \\
\hline \multirow{4}{*}{ Financial Development } & DCBS & \multirow{6}{*}{$\begin{array}{l}\text { does not Granger } \\
\text { cause GDPG }\end{array}$} & 0.9780 & [0.3881] \\
\hline & DCPS & & 0.4833 & [0.6212] \\
\hline & M3 & & 2.7631 & [0.0782] \\
\hline & GDS & & 0.7745 & {$[0.4694]$} \\
\hline \multirow{2}{*}{ Real Sector } & TRADE & & 0.3820 & {$[0.6856]$} \\
\hline & GCE & & 0.7359 & [0.4870] \\
\hline
\end{tabular}


Figure 1

Impulse Response Functions of annual GDP Growth Rate to Cholesky-One- StandardDeviation Innovations

Panel A: All the geographic regions from the panel dataset
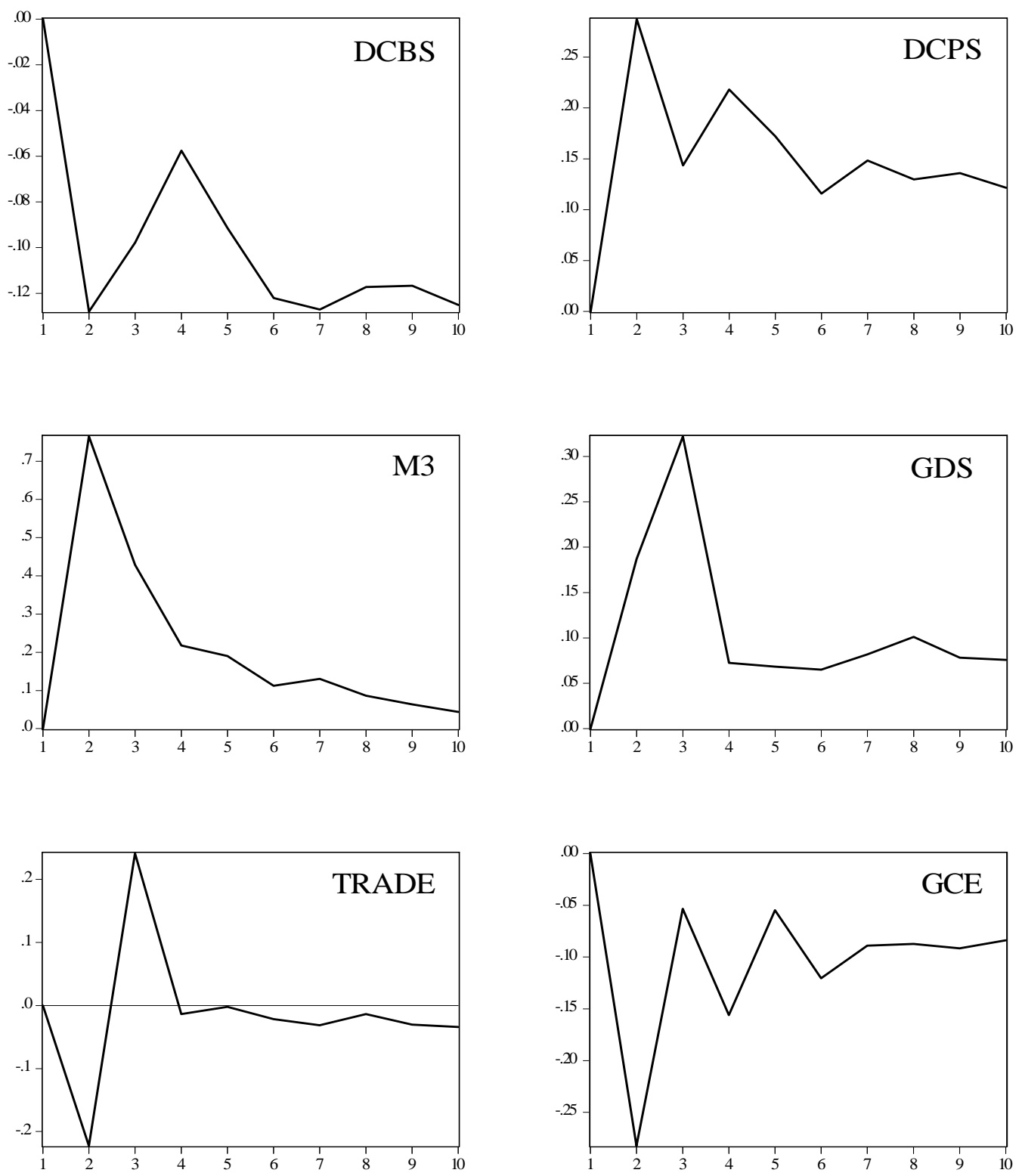

Note: The horizontal axis is the number of years following the shock indicated in each plot and the vertical axis is the growth rate of GDP. 
Panel B: Classification by geographic regions

High-Income OECD
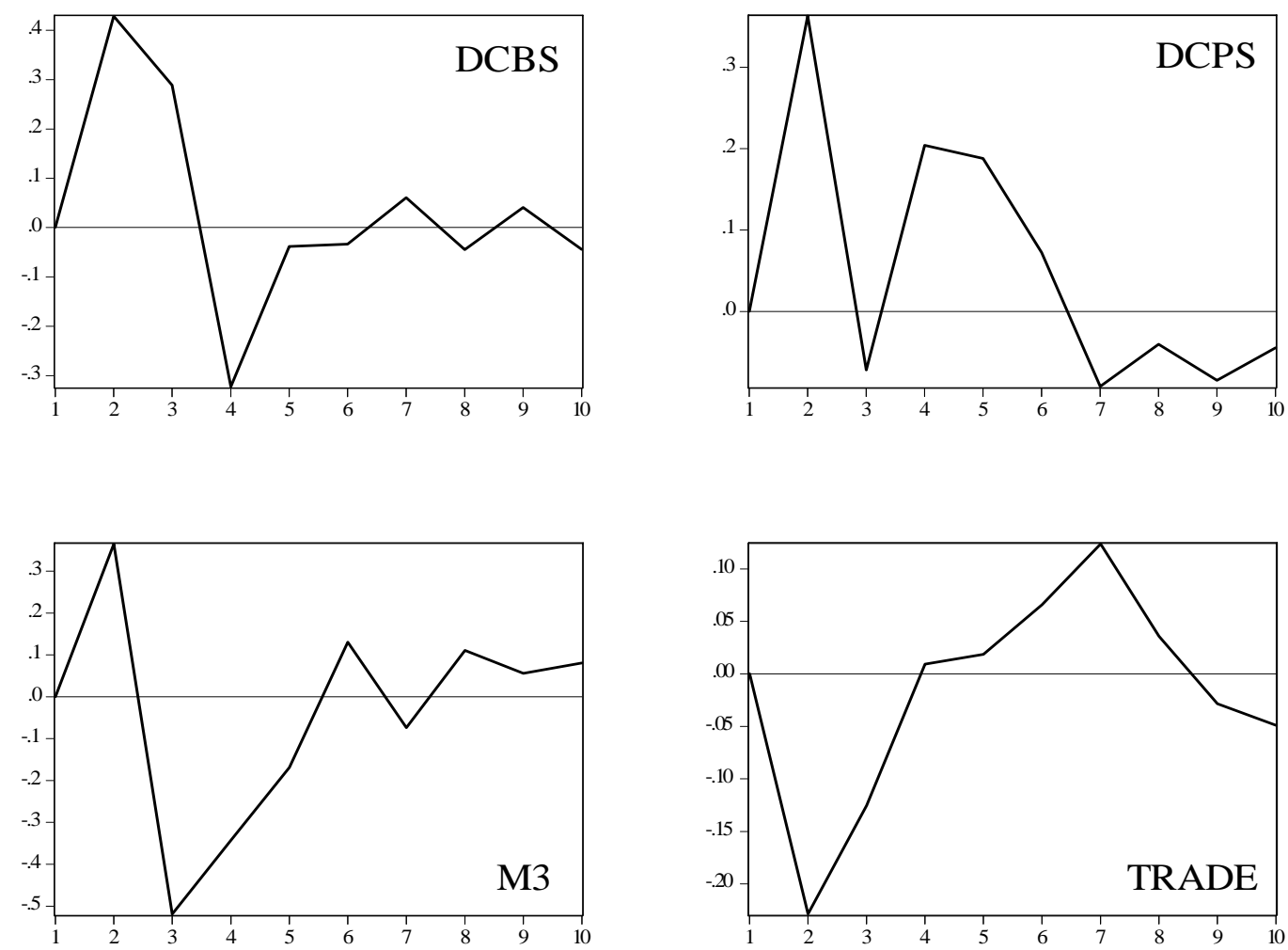

Latin America \& Caribbean

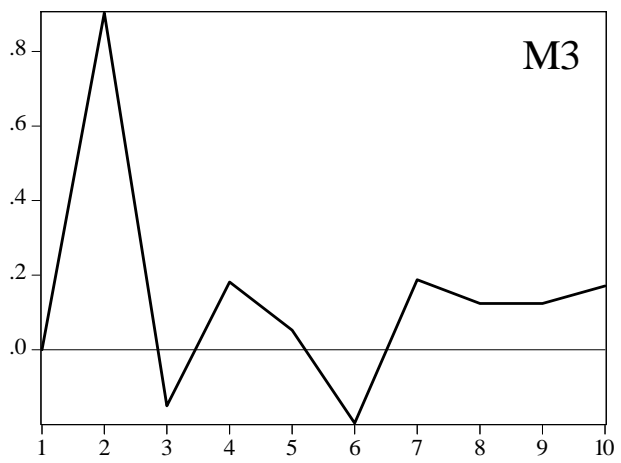

Middle East \& North Africa

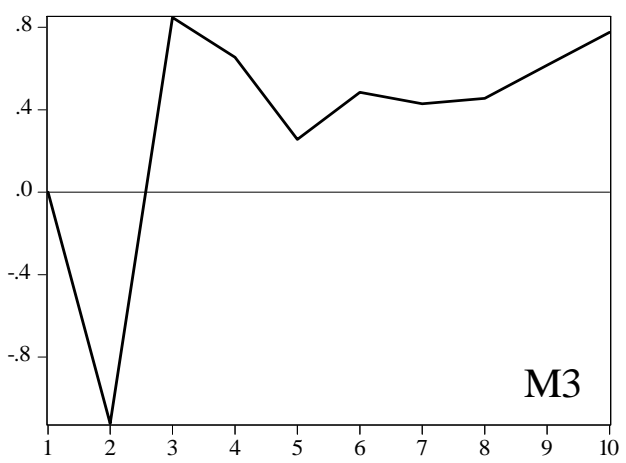

Note: The horizontal axis is the number of years following the shock indicated in each plot and the vertical axis is the growth rate of GDP. 